\title{
CARACTERIZAÇÃo de CINZA DE CASCA DE ARROZ PARA USO COMO MATÉRIA-PRIMA NA FABRICAÇÃO DE REFRATÁRIOS DE SÍLICA
}

\author{
Viviana Possamai Della, Ingeborg Kühn e Dachamir Hotza \\ Departamento de Engenharia Mecânica/Departamento de Ciência e Engenharia de Materiais, Universidade Federal de Santa Catarina, \\ CP 476, 88040-900 Florianópolis - SC
}

Recebido em 15/9/00; aceito em 23/5/01

\begin{abstract}
CHARACTERIZATION OF RICE HUSK ASH FOR USE AS RAW MATERIAL IN THE MANUFACTURE OF SILICA REFRACTORY. The characterization of rice husk ash, a deriving byproduct of the burning of the rice husk during the rice processing is the object of this study. This byproduct, for being rich in silica, can be an important raw material for the production of siliceous ceramics, such as thermal insulators and refractory. A combination of surface analysis, thermal analysis and microscopy analysis techniques was used for the characterization. The characterized by-product presented as main component the silica, under amorphous form, with a maximum content of alkalis around $1 \%$, features that become it potentially interesting for the production of ceramic materials.
\end{abstract}

Keywords: rice husk ash; silica; refractory.

\section{INTRODUÇÃO}

Com o objetivo de reduzir a geração de resíduos nos processos industriais e agrícolas, principalmente os poluentes, bem como melhor reaproveitá-los, seja no próprio processo produtivo ou como matéria-prima na elaboração de outros materiais, tem-se cada vez mais investido em pesquisas para a transformação destes, até então considerados apenas resíduos industriais, em subprodutos de interesse comercial.

Com a constante evolução da indústria cerâmica, torna-se cada vez mais necessária a busca de meios tecnológicos que tragam melhorias à relação custo/benefício dos materiais produzidos. O uso de matérias-primas alternativas, mudanças nos processos industriais, bem como a adequação das propriedades às condições de serviço, são pontos de extrema importância na indústria de refratários e produtos cerâmicos em geral.

Do processo de beneficiamento do arroz tem-se como resíduo a casca de arroz (CA), que devido ao seu alto poder calorífico (aproximadamente $16720 \mathrm{~kJ} / \mathrm{kg}$ ) e custo praticamente nulo, vem cada vez mais substituindo a lenha empregada na geração de calor e de vapor, necessários para os processos de secagem e parboilização dos grãos. Mediante a queima da casca de arroz em fornalhas a céu aberto ou em fornos especiais com temperatura controlada, é produzida a cinza de casca de arroz (CCA), denominada residual quando é obtida sem controle de temperatura e tempo de exposição.

A estimativa para produção nacional de arroz em casca para a safra 2000/2001, segundo dados do IBGE $^{1}$ é de aproximadamente 11.089.788 toneladas. No Brasil a região Sul apresenta a maior produção com cerca de 5.957.569 toneladas, onde o estado do Rio Grande do Sul é o maior produtor nacional, com estimativa de safra em torno de 4.986.875 toneladas, o que representa cerca de $44,9 \%$ da produção nacional. Santa Catarina ocupa o $3^{\circ}$ lugar com 799.031 toneladas representando $7,2 \%$ da produção nacional.

Considerando que do total de arroz colhido $23 \%$ correspondem à casca e $4 \%$ correspondem à cinza, conclui-se que 443.591 toneladas deste resíduo são geradas no país. Deste total o estado do Rio Grande do Sul contribui com 199.475

\footnotetext{
*e-mail: viviana@pg.materiais.ufsc.br
}

toneladas e Santa Catarina com 31.961 toneladas de cinza somente no ano de 2000.

Durante o processo de beneficiamento do arroz, resulta como subproduto a casca de arroz, que representa cerca de $23 \%$ do peso do arroz. Esta casca devido a sua alta dureza, fibrosidade e natureza abrasiva, leva a obtenção de produtos de baixa propriedade nutritiva, boa resistência ao desgaste e muita cinza ${ }^{2}$. Atualmente, parte desta casca está sendo utilizada na fabricação de blocos e painéis empregados na construção civil, onde substitui a fibra de madeira comumente utilizada ${ }^{3}$. Uma grande quantidade desta casca é reaproveitada dentro da própria usina de beneficiamento do arroz onde, a partir da sua combustão, é gerado calor para a parboilização dos grãos. Como resíduo desta combustão, é produzida a cinza de casca de arroz. Esta cinza, até então útil somente para estabilização de solos (ainda sem comprovação técnica) e aterros sanitários, devido ao seu elevado teor de óxido de silício, está sendo utilizado, segundo Fonseca ${ }^{2}$, na fabricação de vidros, isolantes térmicos, tijolos prensados e materiais refratários, bem como na produção de cimento portland e na forma de agregado em argamassas e concretos ${ }^{3}$.

A CCA é um subproduto rico em sílica (teores superiores a $90 \%$ ), que pode ser usada como componente principal de massas cerâmicas para a produção de refratários silicosos ácidos. Este tipo de refratário a base de sílica possui ótimas propriedades, tal como alta resistência mecânica em temperaturas elevadas, maior que a dos tijolos feitos a base de argila e, por isso, tem como aplicação a fabricação de abóbadas de fornos de grande porte ${ }^{4}$

A fabricação de materiais cerâmicos do tipo refratário ou isolante que utilizem a cinza de casca de arroz (Figura 1) seja como componente principal ou como secundário, é uma alternativa para solucionar o problema da disposição das cinzas no meio ambiente, além de gerar um produto de maior valor agregado sem que haja a produção de um novo resíduo.

\section{MATERIAIS E MÉTODOS}

Foram realizados ensaios de análise térmica diferencial (ATD) e termogravimétrica (TG), utilizando-se um equipamento de análise térmica simultânea Netzsch ST409, na temperatura de $1400^{\circ} \mathrm{C}$ a uma taxa de aquecimento de $10^{\circ} \mathrm{C} / \mathrm{min}$.

A análise de difração de raios-X (DRX) foi realizada no difratômetro XPERT da Phillips, com tubo de $\mathrm{Cu}(\mathrm{K} \alpha)$. A 


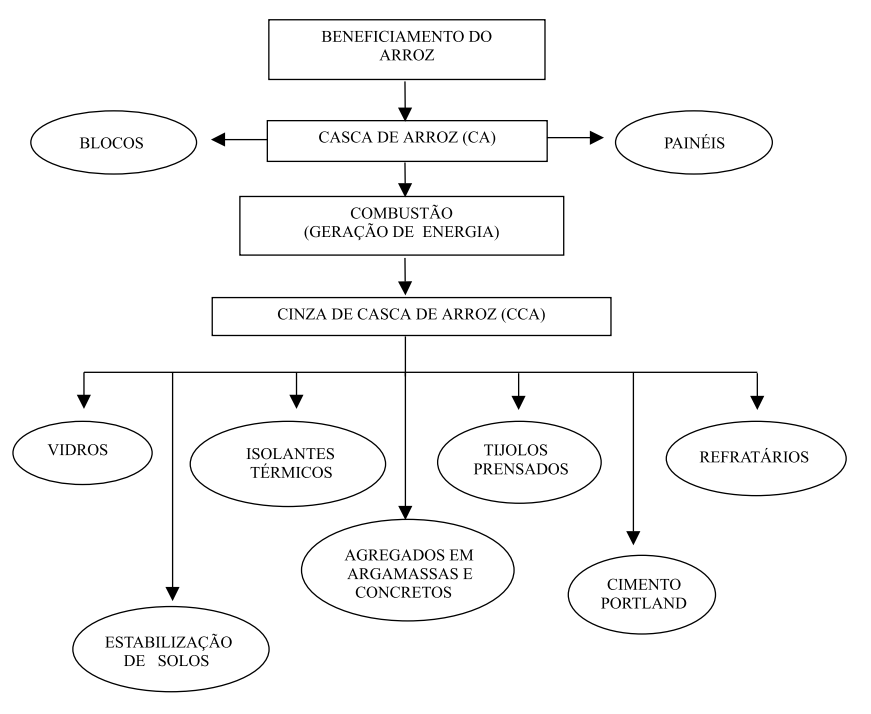

Figura 1. Organograma de aplicação da cinza de casca de arroz a partir do beneficiamento do arroz.

cinza de casca de arroz, na forma de pó, encontrava-se orientada aleatoriamente.

$\mathrm{O}$ valor de área superficial da cinza foi determinado pelo método B.E.T. (Brunauer, Emmett e Teller) por adsorção de nitrogênio, em equipamento Micromeritics, modelo ASAP 2000.

Para determinação da distribuição granulométrica da CCA foi adotado o método de peneiramento a seco segundo procedimento da AICE (apud [5]), e a técnica de difratometria a laser utilizando-se o equipamento Cilas $1064 \mathrm{~L}$, que usa água destilada como meio suspensor a temperatura de $23,0 \pm 1^{\circ} \mathrm{C}$.

A umidade residual da cinza foi determinada através da diferença percentual de peso da cinza in natura e após secagem em estufa a $60^{\circ} \mathrm{C}$ durante 48 horas, segundo a norma brasileira MB-15/NBR-8293/1983.

O teor de carbono foi determinado (a) através da média obtida pelo método de calcinação em forno tubular a temperatura de $500^{\circ} \mathrm{C}$ por $90 \mathrm{~min}$, segundo metodologia do IPT (Instituto de Pesquisas Tecnológicas/USP); e (b) pelo método gravimétrico, por titulação com solução de hidróxido de bário, segundo metodologia descrita em Vogel ${ }^{6}$.

A determinação do teor de materiais voláteis foi feita conforme especificações da norma brasileira MB-15/NBR-8290/ Dez 1983, em mufla Quimis.

A densidade picnométrica foi determinada no picnômetro Nova 1000 da Quantachrome, estando o material sob a forma de pó.

Para a caracterização microestrutural, a CCA foi depositada sobre fita de carbono e então recoberta com fino filme de ouro. Foi então observada em microscópio eletrônico de varredura (MEV) Phillips XL 30. A determinação da composição química qualitativa foi realizada em microssonda com espectrômetro de energia dispersiva (EED) acoplada ao MEV, enquanto que a análise quantitativa foi realizada através da técnica de fluorescência de raios-X (FRX), a partir do resíduo da perda ao fogo a $1000^{\circ} \mathrm{C}$.

Para determinação da fusibilidade (cone de fusão), referente ao método de ensaio 1.24 da AICE (apud [5]), a CCA foi seca e moída até resíduo igual ou inferior a $2 \%$ em malha 200 mesh $(75 \mathrm{~mm})$. A partir desta cinza foram feitos dois cones com dimensões de $35 \mathrm{~mm}$ de altura e $35 \mathrm{~mm}$ de diâmetro. $\mathrm{O}$ processo de queima destes cones iniciou com aquecimento a partir da temperatura ambiente até $1280^{\circ} \mathrm{C}$, seguindo uma taxa de aquecimento de $5^{\circ} \mathrm{C} / \mathrm{min}$, com um patamar de queima de $6 \mathrm{~min}$ nesta temperatura. Após resfriamento foram medidas as variações dimensionais dos cones quanto à altura e diâmetro.

\section{RESULTADOS E DISCUSSÃO}

A Tabela 1 apresenta a análise química da amostra de CCA utilizada neste trabalho, que foi determinada por FRX e, para efeito de comparação, uma composição típica encontrada na literatura ${ }^{7}$.

Tabela 1. Composição química, em óxidos, da cinza de casca de arroz analisada neste experimento em comparação com a composição típica de refratários de sílica.

\begin{tabular}{ccc}
\hline & \multicolumn{2}{c}{ Percentual em Massa } \\
\cline { 2 - 3 } Óxidos & $\begin{array}{c}\text { Amostra de CCA } \\
\text { analisada }\end{array}$ & $\begin{array}{c}\text { Composição Típica } \\
\text { Singer }\end{array}$ \\
\hline $\mathrm{SiO}_{2}$ & 97,87 & $92-96$ \\
$\mathrm{Al}_{2} \mathrm{O}_{3}$ & 0,13 & $0,5-3,0$ \\
$\mathrm{Fe}_{2} \mathrm{O}_{3}$ & 0,06 & $0,5-2,5$ \\
$\mathrm{CaO}$ & 0,50 & $1,5-3,0$ \\
$\mathrm{MgO}$ & 0,74 & \\
$\mathrm{~K}_{2} \mathrm{O}$ & 0,88 & $0,3-1,5$ \\
$\mathrm{Na} 2 \mathrm{O}$ & 0,12 & - \\
$\mathrm{MnO}_{\mathrm{TiO}}$ & 0,25 & - \\
$\mathrm{P}_{2} \mathrm{O}_{5}$ & 0,01 & - \\
\hline
\end{tabular}

(-) valor não especificado pelo autor

Esta análise química revelou um percentual de $\mathrm{SiO}_{2}$ de $96,65 \%$, tendo como principais impurezas (em quantidades inferiores a $1 \%) \mathrm{K}_{2} \mathrm{O}, \mathrm{CaO}, \mathrm{Al}_{2} \mathrm{O}_{3}, \mathrm{MgO}$ e $\mathrm{P}_{2} \mathrm{O}_{5}$. Dentre os óxidos detectados, $\mathrm{K}_{2} \mathrm{O}, \mathrm{CaO}$ e $\mathrm{P}_{2} \mathrm{O}_{5}$, são considerados fundentes e formadores de fase vítrea, uma vez que tendem a baixar o ponto de fusão e por isto são indesejáveis em materiais refratários.

Segundo Nakata et $\mathrm{al}^{8}$, o potássio contido na CCA, acelera tanto a fusão das partículas quanto à cristalização da sílica amorfa em cristobalita por abaixar o ponto de fusão do material. A composição química da cinza varia em função do solo em que o arroz é plantado, dos tipos e teores de fertilizantes utilizados, bem como do tipo de arroz propriamente dito?

Comparando o percentual de óxidos obtidos na amostra com valores da literatura, nota-se que o teor de $\mathrm{SiO}_{2}$ está acima do comumente encontrado, e que o percentual dos outros elementos está abaixo dos valores padrão, com exceção dos álcalis que apresentaram um teor dentro da média. Estes resultados indicam que a matéria-prima em análise neste trabalho apresenta composição química favorável à produção de refratários silicosos, não necessitando, em princípio, correção de composição por adição de outras matérias-primas.

A análise mineralógica mostrou que a cinza apresenta sílica na forma amorfa (Figura 2). A presença de sílica amorfa (reativa) ou cristalina (praticamente inerte) está diretamente ligada à temperatura e ao método de obtenção da cinza. Quando a temperatura de queima da CCA é baixa ou quando o tempo

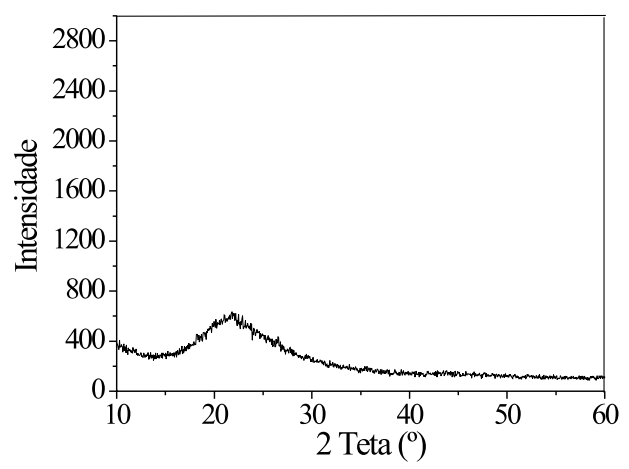

Figura 2. Difratograma de raios- $X$ da cinza de casca de arroz. 
de exposição da mesma a altas temperaturas é pequeno, a sílica contida na cinza é predominantemente amorfa ${ }^{3}$.

Considerando que a fase predominante seja óxido de silício, os outros elementos detectados pela análise química devem estar presentes na cinza sob a forma de solução sólida, uma vez que os mesmos não mostraram picos característicos de fases, provavelmente devido ao seu teor bastante baixo.

$\mathrm{O}$ valor encontrado para a área superficial da cinza utilizada nesta caracterização foi de $177 \mathrm{~m}^{2} / \mathrm{g}$. Segundo Nakata ${ }^{8}$, as cinzas oriundas de cascas queimadas a $400^{\circ} \mathrm{C}$ possuem área superficial em torno de $147 \mathrm{~m}^{2} / \mathrm{g}$, quando queimadas a $800^{\circ} \mathrm{C}$ possuem área superficial de $5 \mathrm{~m}^{2} / \mathrm{g}$ e acima de $900^{\circ} \mathrm{C}$ o valor oscila entre 0,8 e $0,4 \mathrm{~m}^{2} / \mathrm{g}$. A tendência ao decréscimo da área superficial com o aumento da temperatura está relacionada com o fato da superfície das partículas sofrerem fusão e agregaremse umas às outras ${ }^{8}$.

Com o resultado da distribuição granulométrica via laser (Figura 3), verifica-se que o tamanho médio das partícula está em torno de $40 \mu \mathrm{m}(0,040 \mathrm{~mm})$. Não há partículas com tamanho superior a $140 \mu \mathrm{m}(0,14 \mathrm{~mm})$. Cerca de $8 \%$ tem tamanho inferior a $5 \mu \mathrm{m}$, o que pode ser problemático do ponto de vista de segurança dos trabalhadores envolvidos em um processo que tenha a CCA como matéria-prima. Conforme Rey ${ }^{10}$, a exposição a partículas de sílica com tamanho inferior a $5 \mu \mathrm{m}$, por um período de 5 a 10 anos (dependendo da concentração das poeiras na atmosfera), ocasiona uma doença denominada silicose que compromete as vias respiratórias podendo inclusive causar câncer.

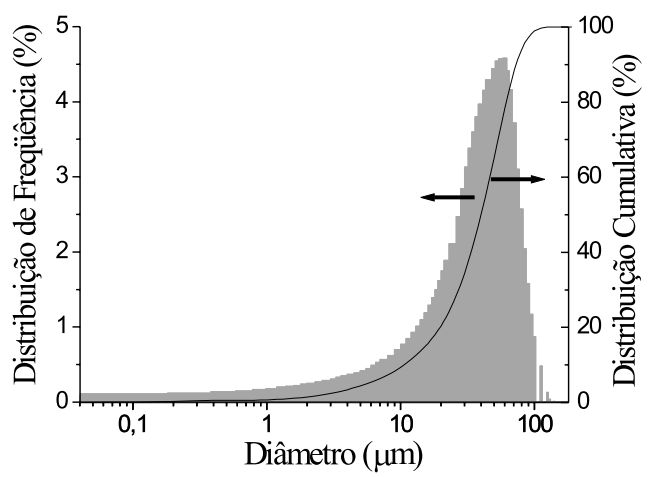

Figura 3. Distribuição granulométrica das cinzas de casca de arroz obtidas por difratometria a laser.

A Tabela 2 apresenta o resultado da distribuição granulométrica via peneiramento a seco.

Tabela 2. Distribuição granulométrica da cinza de casca de arroz via peneiramento a seco.

\begin{tabular}{cc}
\hline Peneira & \% Retido \\
\hline$\# 16(>100 \mu \mathrm{m})$ & 0,5 \\
$\# 32(500$ a $1000 \mu \mathrm{m})$ & 8,7 \\
$\# 60(250$ a $500 \mu \mathrm{m})$ & 27,8 \\
$\# 115(125$ a $250 \mu \mathrm{m})$ & 30,5 \\
\# 270 $(53$ a $125 \mu \mathrm{m})$ & 20,7 \\
Passante \# $270(<53 \mu \mathrm{m})$ & 11,8 \\
\hline
\end{tabular}

A diferença observada entre as duas técnicas utilizadas para a determinação da distribuição granulométrica pode ser atribuída à forma de realização do ensaio. Como o peneiramento é realizado a seco, avalia-se neste método o tamanho das partículas e dos aglomerados simultaneamente. Já na difração a laser, verifica-se a dispersão dos aglomerados, uma vez que, para o ensaio, o pó é suspenso em água destilada e submetido à agitação, resultando em menores valores.
O teor de umidade residual ficou em torno de $3 \%$, considerado por Fonseca ${ }^{2}$ dentro da faixa de umidade natural da cinza, que varia de 1 a $4 \%$.

O percentual médio de carbono detectado pelas técnicas de análise utilizadas foi de $8,8 \%$. O aumento ou o decréscimo da quantidade de carbono na CCA é resultante da quantidade de oxigênio livre na combustão ${ }^{2}$.

A cinza apresentou cerca de $0,3 \%$ de materiais voláteis, valor comparável à faixa de 0,37 a $1,47 \%$ encontrada por Fonse$\mathrm{ca}^{2}$. Segundo este autor, $\mathrm{Cl}, \mathrm{Br}$ e $\mathrm{SO}_{3}$ são substâncias voláteis normalmente encontrados na CCA.

A densidade picnométrica apresentou valor médio em torno de $1,3 \mathrm{~g} / \mathrm{cm}^{3}$, cerca de $59 \%$ do valor encontrado por Reed ${ }^{11}$ $\left(2,20 \mathrm{~g} / \mathrm{cm}^{3}\right)$ para a sílica vítrea, o que indica que as partículas de CCA são mais leves, ou seja, mais porosas em relação a sílica vítrea. A densidade da cinza é função da temperatura de queima $^{3}$. O aumento da temperatura leva à redução da quantidade de substâncias voláteis e, em consequiência, ao aumento da porosidade interna da cinza, inferindo assim sobre sua densidade.

A partir das análises térmica diferencial e termogravimétrica (Figura 4) constatou-se que entre $50^{\circ} \mathrm{C}$ e $600^{\circ} \mathrm{C}$ na curva da análise termogravimétrica (TG), tem-se uma perda de massa de $22,5 \%$ decorrente da eliminação da água adsorvida sobre as partículas de cinza, água de constituição, combustão de carbono e liberação de substâncias voláteis presentes.

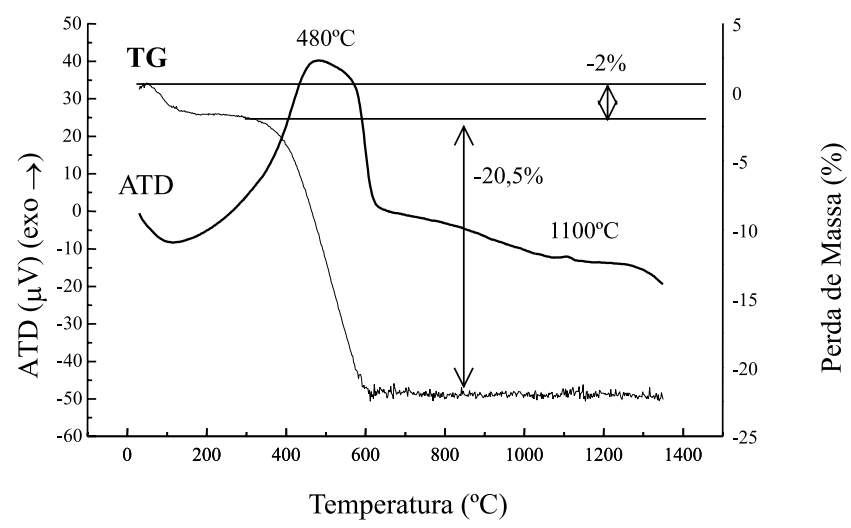

Figura 4. Resultado das análises térmica diferencial e termogravimétrica da cinza de casca de arroz.

Entre $50^{\circ} \mathrm{C}$ e $200^{\circ} \mathrm{C}$ ocorreu uma perda de massa em torno de $2 \%$ devido basicamente à eliminação de água adsorvida superficialmente. Nesta mesma faixa de temperatura, observa-se um pico endotérmico aproximadamente por volta de $100^{\circ} \mathrm{C}$ na curva de análise térmica diferencial (ATD), também devido à perda de água adsorvida, etapa que se completa por volta dos $200^{\circ} \mathrm{C}$. Entre $300^{\circ} \mathrm{C}$ e $600^{\circ} \mathrm{C}$, observa-se a maior perda de massa, em torno de 20,5\% devido à eliminação de água de constituição, materiais voláteis e combustão de carbono. Em $480^{\circ} \mathrm{C}$ evidencia-se um pico exotérmico na curva de ATD característico da combustão do carbono, o qual permanece na cinza após a queima da casca, a eliminação da água de constituição e materiais voláteis, que coincide com a curva de TG nesta faixa de temperatura. Não foi evidenciada a presença de nenhum pico característico de formação de fase antes de $1000^{\circ} \mathrm{C}$. A $1100^{\circ} \mathrm{C}$, observou-se um pequeno pico exotérmico referente a máxima cristalização da fase cristobalita.

A caracterização microestrutural da cinza, (Figura 5), mostrou a presença de partículas grandes $(\sim 1 \mathrm{~mm})$ e pequenas $(<$ $0,5 \mathrm{~mm}$ ), predominando as menores (Figura 5a).

$\mathrm{O}$ formato alongado e contorcido, com aparência de espiga de milho ${ }^{12}$, é provocado pelo processo de queima (Figura 5b). 

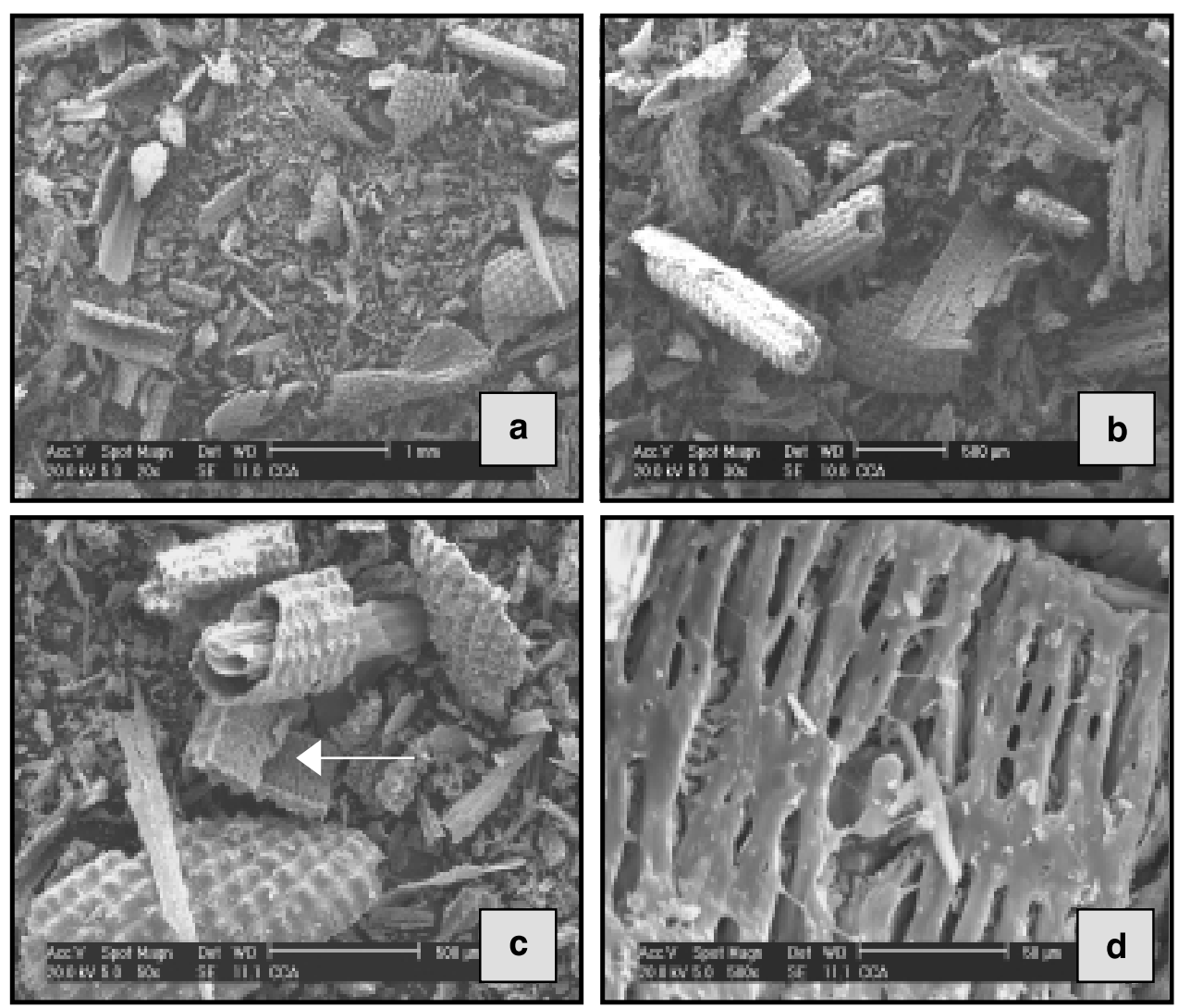

Figura 5. Características típicas da cinza de casca de arroz: (a) distribuição granulométrica variada; (b) aspecto morfológico;

(c) epidermes internas e externas em destaque; (d) estrutura da epiderme interna da cinza vista em (c).

A Figura 5c apresenta as epidermes internas e externas das CCA. A Figura 5d mostra, com maior detalhamento, a epiderme interna de uma das partículas de casca de arroz presente na cinza e vista em (c). Nota-se que a mesma apresenta uma estrutura celular e porosa resultante da remoção de lignina e celulose presentes na casca durante a queima, uma vez que a celulose é o maior constituinte orgânico da casca.

Com base no exposto por James ${ }^{13}$, a sílica presente na cinza está concentrada primeiramente dentro da epiderme externa em direção ao meio da estrutura da casca, porém, uma pequena, mas significante quantidade de sílica reside dentro da epiderme interna, adjacente ao grão de arroz.

De acordo com a análise química por EED (Figura 6), constatou-se que os elementos em maior concentração foram o oxi-

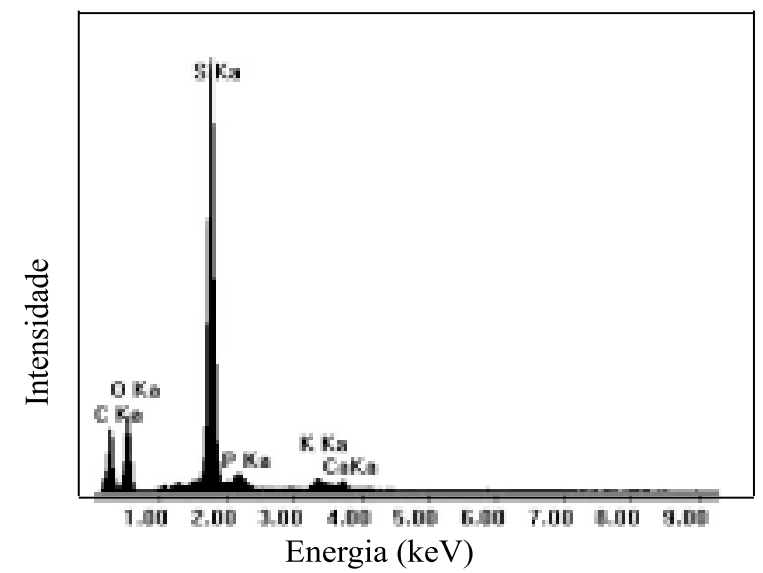

Figura 6. Análise química por EED apresentando os principais constituintes da mistura. gênio (teores entre 26 a 40\%) e o silício (teores entre 52 a $73 \%$ ), que estão combinados sob a forma de óxido de silício.

Como a análise foi realizada em pequenas regiões, constatou-se em alguns pontos a presença de elementos como cálcio, potássio e fósforo em quantidades inferiores a $1 \%$.

A CCA empregada nesta caracterização apresenta coloração preta, quando analisada macroscopicamente. Conforme exposto por $\mathrm{Santos}^{3}$, a casca de arroz queimada parcialmente gera uma cinza com teor de carbono mais elevado e, em conseqüência, de coloração preta; quando inteiramente queimada, resulta em uma cinza de cor acinzentada, branca ou púrpura, cuja cor é fortemente dependente das impurezas presentes e das condições de queima.

De acordo com o teste de fusibilidade (cone de fusão), Tabela 3, considera-se esta CCA um material com características refratárias, pois o cone de fusão apresentou pequenas variações nas suas dimensões quando queimado a $1280^{\circ} \mathrm{C}$.

Tabela 3. Modificações sofridas pelo cone de fusão.

\begin{tabular}{lccc}
\hline & Inicial & Final & Variação Dimensional \\
\hline Diâmetro & $35,0 \mathrm{~mm}$ & $32,5 \mathrm{~mm}$ & $2,5 \mathrm{~mm}(7,1 \%)$ \\
Altura & $35,0 \mathrm{~mm}$ & $31,7 \mathrm{~mm}$ & $3,3 \mathrm{~mm}(9,4 \%)$ \\
\hline
\end{tabular}

\section{CONCLUSÕES}

Uma das maiores potencialidades do uso da cinza de casca de arroz está na fabricação de materiais refratários à base de sílica. O alto ponto de fusão, a baixa densidade picnométrica e a alta porosidade, aliados à grande disponibilidade e ao baixo custo da cinza, são indicativos de um material em potencial para a fabricação de tijolos refratários como os necessários em fornos siderúrgicos. 
Foi observado que a CCA analisada tem como características:

- elevado teor de óxido de silício, presente sob a forma amorfa, o que torna a CCA uma fonte natural e renovável de sílica;

- teores bastante baixos (inferiores a 1\%) de óxidos fundentes, que, por sua vez, baixam o índice de refratariedade do material;

- elevado teor de carbono, que mostra que a CCA foi queimada a baixa temperatura;

- sílica amorfa como constituinte básico, com predominância de partículas pequenas e de formato alongado e contorcido;

\section{AGRADECIMENTOS}

Os autores agradecem à Indústria e Comércio de Arroz Fumacense Ltda pelo fornecimento do material para estudo, e a CAPES pelo auxílio financeiro na forma de bolsa de mestrado.

\section{REFERÊNCIAS}

1. IBGE Instituto Brasileiro de Geografia e Estatística, Divisão de Pesquisas - DIPEQ/SC. Levantamento Sistemático da Produção Agrícola, Florianópolis, Ago., 2001.
2. Fonseca, M.R.G.; Tese de Doutorado; UFRGS, Porto Alegre, RS, 1999.

3. Santos, S.; Dissertação de Mestrado; UFSC, Florianópolis, SC, 1997.

4. Shreve, R. N.; Indústria de Processos Químicos; $4^{\mathrm{a}}$ ed., Ed. Guanabara Dois, Rio de Janeiro, 1980, p 132.

5. Enrique, J.; Negre, F.; Blasco, A.; Beltrán, V.; Controles de Fabricación: Pavimentos y Revestimientos Cerámicos; Ed. AICE; Castellón, 1989.

6. Vogel, A. I., Jeffery, G. H.; Vogel's Textbook of Quantitative Chemical Analysis; $5^{\mathrm{a}}$ ed., Ed. Longman Sci. \& Techn.; Harlow, 1989.

7. Singer, F.; Singer, S.S.; Industrial Ceramics; Ed. Chapman \& Hall; London, 1971, p 1223.

8. Nakata, Y.; Suzuki, M.; Okutani, T.; et al.; J. Ceram. Soc. Jpn.. Inter. 1989, 97, 830.

9. Gava, G.P.; Dissertação de Mestrado; UFSC, Florianópolis, SC, 1999.

10. Rey, L.; Dicionário de Termos Técnicos de Medicina e Saúde; Ed. Guanabara Koogan; Rio de Janeiro, 1999, p 825.

11. Reed, J.S.; Principles of Ceramics Processing; $2^{\mathrm{a}}$ ed., Ed. John Wiley; New York, 1938, p 640.

12. Amick, J.A.; Solid-State Sci. Technol. 1982, 129, 864.

13. James, J.; Rao, M.S.; Thermochim. Acta 1985, 97, 329. 